RESEARCH ARTICLE

\author{
(1) Sokoto Journal of Veterinary Sciences \\ http://dx.doi.org/10.4314/sokjvs.v17i1.7 \\ Konzing et al./Sokoto Journal of Veterinary Sciences, 17(1): 56 - 61.
}

\title{
A retrospective study of dog bite cases reported to some hospitals in Plateau State, Nigeria
}

\author{
L Konzing $^{1 *}$, JKP Kwaga ${ }^{2}$, GSN Kia ${ }^{2}$ \& HM Kazeem ${ }^{3}$ \\ 1. Diagnostics and Extension Division, Shendam Outstation Laboratory, National Veterinary \\ Research Institute (NVRI) Vom, Plateau State, Nigeria \\ 2. Department of Veterinary Public Health and Preventive Medicine, Faculty of Veterinary Medicine, \\ Ahmadu Bello University Zaria, Nigeria \\ 3. Department of Veterinary Microbiology, Faculty of Veterinary Medicine, Ahmadu Bello University, \\ Zaria, Nigeria
}

*Correspondence: Tel.: +2348039737919; E-mail: levivet@yahoo.com

\begin{abstract}
Copyright: (c) 2019 Konzing et al. This is an open-access article published under the terms of the Creative Commons Attribution License which permits unrestricted use, distribution, and reproduction in any medium, provided the original author and source are credited.
\end{abstract}

Publication History:

Received: 11-10-2018

Accepted:28-01-2019

\section{Abstract}

Dog bite exposes victims to many potential zoonoses, particularly rabies which is feared because of its extremely high fatality rate of almost $100 \%$. This study was carried out to evaluate the incidences of dog bite reported to some human hospitals in Plateau State, Nigeria and to provide data that will help in planning of rabies control programmes in the state. Information retrieved from the hospitals include date of bite, location of bite, age and sex of the victims for the period of January, 2007 to December, 2016. Descriptive statistics was used to analyze the data and the results were presented in tables. A total of 884 dog bite cases were reported in 9 hospitals visited across the state; the highest cumulative number ( 85 cases) was reported in April followed by 84 cases in May and 81 cases in October. Furthermore, there were more male (53.39\%) victims of dog bite than female (46.61\%) victims as well as more adult (53.51\%) victims than children (46.49\%) below 15 years of age. It can be concluded from this study that there is a high incidence of dog bite cases in the state. The presence of two popular dog markets located in Jos South and Kanke Local Government Areas of Plateau state could possibly play a significant role in the high incidences of dog bite cases recorded in this study. Hospitals in Plateau State should endeavor to improve on their record keeping of dog bite cases as this will help health workers in planning of rabies control programmes.

Keywords: Dog Bite, Hospital, Plateau State, Retrospective Study

\section{Introduction}

Rabies is exceptionally fatal encephalitis caused by a Lyssavirus in the family Rhabdoviridae transmitted through the bite rabid dogs, but in rare instances by scratches (Goonaratna et al., 1997). Dog bite poses a major public health threat both in developed and developing nations. In addition to the severe physical trauma and potentially permanent disfiguring wounds, dog bite victims often go through emotional pain (Chornel \& Trotignons, 1992).

Bites from dogs expose victims to many potential zoonoses, particularly rabies which is feared because 
of the extremely high fatality rate of almost $100 \%$ (Peters et al., 2004). In addition, reports from rabies endemic areas have consistently indicated that apparently healthy dogs could shed rabies virus in their saliva for long periods without showing signs and symptoms of the disease (Fekadu, 1975). It is globally recognised that the number of rabies related deaths officially reported in most developing countries greatly underestimates the true incidence of the disease, with several factors contributing to widespread underreporting (WHO, 2005; WHO, 2013).

Based on published reports, dog bite cases have been reported in some parts of Nigeria, including Plateau State. Bata et al. (2011) reported a total of 247 dog bite cases between May, 2009 and June, 2010 presentd to ECWA Veterinary Clinic Bukuru, Plateau State, Nigeria. Garba et al. (2014) reported 223 dog bite cases from 11 hospitals in Niger State, Nigeria over a period of 8 years. Hence, the need to carry out further study on dog bite cases reported to some hospitals in Plateau State became necessary. Plateau State is also known to have one of the most flourishing dog markets in Nigeria, where slaughter and purchase of dogs and dog products take place (Sabo et al., 2008). There is a possibility of these markets contributing to the increased incidence of dog bite cases in the State as prevalences reported (Sabo et al., 2008; Sabo, 2009; Konzing, 2014; Konzing et al., 2015).

This study will help to provide information and data that will help in the planning of rabies control programmes in Plateau State and Nigeria at large.

\section{Materials and Methods}

Ethical clearance

Before the commencement of the study, ethical clearance was obtained from the Plateau State Ministry of Health and Plateau State Hospital Management Board through the Department of Veterinary Public Health and Preventive Medicine, Ahmadu Bello University Zaria.

\section{Study area}

Plateau State is located in the middle belt of Nigeria. It is surrounded by Bauchi State to the North East, Kaduna State to the North West, Nassarawa State to the South West and Taraba State to the South East. The state is located between $9.2^{\circ}$ and $9.4^{\circ} \mathrm{N}$, and between $9.3^{\circ}$ and $9.4^{\circ} \mathrm{E}$. The altitude ranges from around 1,200 meters (about 4000 feet) to a peak of 1,829 metres above sea level in the Shere Hills range near Jos. It has an area of 26,889 square kilometres, and is celebrated as "The Home of Peace and Tourism", with an estimated population of about 3.5 Million people (Blench et al., 2003). The population of the state is made up of urban and rural dwellers; the rural dwellers are predominantly peasant farmers who are also involved in socioeconomic activities like animal rearing. The urban dwellers are mostly civil servants, industrialists and traders. Dog markets are located at Dawaki in Kanke Local Government Area (LGA) and Bukuru in Jos South LGA (Sabo et al., 2008; Konzing et al., 2015). No veterinary services and provided and no vaccination of dogs is practiced at the dog markets. The state has over forty ethno-linguistic groups which includes; "Berom", "Hausa”, "Mwaghavul”, "Ngas", "Taroh" "Goemai", etc (Blench et al., 2003).

\section{Study design}

Three general hospitals, three missionary hospitals, two primary health care providers and one tertiary health care provider were selected and visited across the three senatorial zones of the State. Information retrieved from the hospitals included date of bite, location of bite, age and sex of the victims for the period of January, 2007 to December, 2016.

\section{Statistical analysis}

Chi-square test using the statistical packages for social sciences (SPSS) software version 22 was used to analyse the data and the P-value obtained was used to test for statistical significance of the variables and the results were presented on tables.

\section{Results}

A total of 884 dog bite cases were reported in the nine hospitals visited during the period (January, 2007 - December, 2016) of this study. The findings of this study showed that the highest number of cases (146 cases) occurred in the year 2009 and the least (37 cases) was reported in 2007 (Table 1). Vom Christian Hospital (VCH) documented the highest number of cases (425 cases) and the least (5 cases) was reported by COCIN Comprehensive Hospital, Mangu. However, there were no records of dog bites from Our Lady of Apostle Hospital Zawan, Pankshin General Hospital and Mikang General Hospital (Table $1)$.

The highest cumulative number of cases (85 cases) was reported in April followed closely by 84 cases in May and only 51 cases in January as the least for the 10-year study period (Table 2).

Furthermore, there were more male (53.39\%) victims of dog bite than female (46.61\%) victims, 
Table 1: Annual distributions of dog bite cases in Plateau State, Nigeria Jan. 2007- Dec. 2016

\begin{tabular}{llllllllllll}
\hline $\begin{array}{l}\text { Year/ } \\
\text { Hospital }\end{array}$ & 2007 & 2008 & 2009 & 2010 & 2011 & 2012 & 2013 & 2014 & 2015 & 2016 & Total \\
\hline VCH & 24 & 38 & 106 & 83 & 17 & 54 & 34 & 25 & 19 & 25 & 425 \\
PSH & 0 & 18 & 20 & 42 & 32 & 36 & 33 & 35 & 17 & 32 & 265 \\
OLA & 0 & 0 & 0 & 0 & 0 & 0 & 0 & 0 & 0 & 0 & 0 \\
Kabwir & 0 & 0 & 7 & 3 & 2 & 0 & 1 & 20 & 16 & 1 & 50 \\
Mangu & 0 & 0 & 0 & 2 & 0 & 2 & 0 & 1 & 0 & 0 & 5 \\
Pankshin & 0 & 0 & 0 & 0 & 0 & 0 & 0 & 0 & 0 & 0 & 0 \\
Langtang & 13 & 12 & 13 & 12 & 8 & 10 & 11 & 12 & 16 & 16 & 123 \\
Tunkus PHC & 0 & 0 & 0 & 0 & 0 & 1 & 3 & 6 & 3 & 3 & 16 \\
Mikang & 0 & 0 & 0 & 0 & 0 & 0 & 0 & 0 & 0 & 0 & 0 \\
Total & 37 & 68 & 146 & 142 & 59 & 103 & 82 & 99 & 71 & 71 & 884 \\
\hline VCH
\end{tabular}

$\mathrm{VCH}=$ Vom Christian Hospital

PSH = Plateau Specialist Hospital

OLA = Our Lady of Apostle Hospital

$\mathrm{PHC}=$ Primary Health Care

Table 2: Monthly distributions of dog bite cases in Plateau State, Nigeria Jan. 2007- Dec. 2016

\begin{tabular}{lllllllllllllll}
\hline $\begin{array}{l}\text { Month/ } \\
\text { Hospital }\end{array}$ & Jan & Feb & Mar & Apr & May & Jun & Jul & Aug & Sep & Oct & Nov & Dec & Total \\
\hline VCH & 28 & 41 & 32 & 37 & 33 & 44 & 29 & 50 & 35 & 38 & 27 & 32 & 425 \\
PSH & 14 & 22 & 37 & 28 & 34 & 35 & 15 & 11 & 11 & 26 & 22 & 20 & 265 \\
OLA & 0 & 0 & 0 & 0 & 0 & 0 & 0 & 0 & 0 & 0 & 0 & 0 & 0 & 5 \\
Kabwir & 1 & 3 & 1 & 3 & 4 & 3 & 1 & 6 & 4 & 8 & 10 & 6 & 50 \\
Mangu & 1 & 0 & 2 & 1 & 0 & 1 & 0 & 0 & 0 & 0 & 0 & 0 & 5 \\
Pankshin & 0 & 0 & 0 & 0 & 0 & 0 & 0 & 0 & 0 & 0 & 0 & 0 & 0 \\
Langtang & 7 & 13 & 8 & 15 & 10 & 7 & 9 & 12 & 12 & 8 & 9 & 13 & 123 \\
Tunkus PHC & 0 & 2 & 2 & 1 & 3 & 0 & 2 & 0 & 2 & 1 & 0 & 3 & 16 \\
Mikang & 0 & 0 & 0 & 0 & 0 & 0 & 0 & 0 & 0 & 0 & 0 & 0 & 0 \\
Total & 51 & 81 & 82 & 85 & 84 & 80 & 56 & 79 & 64 & 81 & 68 & 73 & 884 \\
\hline
\end{tabular}

$\mathrm{VCH}=$ Vom Christian Hospital

PSH = Plateau Specialist Hospital

OLA = Our Lady of Apostle Hospital

$\mathrm{PHC}=$ Primary Health Care

with only a marginal difference of $6.78 \%$ for the study period. There was no statistically significant relationship between the date and the sex of the victims, calculated P-value $(0.492)$ is greater than 0.05 (Table 3).

Age distribution of dog bite cases showed that there were more adult (53.51\%) victims of dog bite than children (46.49\%) below 15 years of age. There was no statistically significant $(p<0.05$ ) relationship between the date and the age of the victims, calculated $\mathrm{P}$-value $(0.065)$ is greater than 0.05 (Table 4).

Location of dog bite sites on the part of the body of the victims indicated that no proper record on the location of dog bite was kept; hence, "unknown" (58.71\%) bite location was the highest. This was followed by the leg (26.81\%) and the least was the abdomen $(0.79 \%)$ of the victims There was statistically significant relationship between the date and the location of the bite on the victims, calculated P-value (0.004) is less than 0.05 (Table 5).

\section{Discussion}

The results of this study revealed that 884 dog bite cases were reported to nine health facilities in Plateau State over the ten-year period which calls for concern due to its public health significance. This is quite disturbing when compared to 223 dog bite cases reported to 11 hospitals in Niger State over eight-year period (Garba et al., 2014). The presence of two popular dog markets in the state located in Jos South and Kanke Local Government Areas (LGA) 
Table 3: Sex distribution of victims of dog bite cases in Plateau State, Nigeria Jan. 2007- Dec. 2016

\begin{tabular}{llllll}
\hline Year/Sex & Male (\%) & Female (\%) & Total (\%) & P-value & Chi square \\
\hline 2007 & $20(2.26)$ & $17(1.92)$ & $37(4.19)$ & 0.49 & 8.42 \\
2008 & $41(4.63)$ & $27(3.05)$ & $68(7.69)$ & & \\
2009 & $66(7.47)$ & $80(9.05)$ & $146(16.52)$ & \\
2010 & $79(8.94)$ & $63(7.13)$ & $142(16.06)$ & \\
2011 & $32(3.62)$ & $27(3.05)$ & $59(6.67)$ & \\
2012 & $59(6.67)$ & $44(4.98)$ & $103(11.65)$ & \\
2013 & $44(4.98)$ & $38(4.30)$ & $82(9.28)$ & \\
2014 & $48(5.43)$ & $51(5.77)$ & $99(11.20)$ & \\
2015 & $37(4.19)$ & $34(3.85)$ & $71(8.03)$ & \\
2016 & $46(5.20)$ & $31(3.51)$ & $77(8.71)$ & & \\
Total & $472(53.39)$ & $412(46.61)$ & $884(100)$ & & \\
\hline
\end{tabular}

Table 4: Age distribution of victims of dog bite cases in Plateau State, Nigeria Jan. 2007- Dec. 2016

\begin{tabular}{llllll}
\hline Year/Age & $>15$ years $(\%)$ & $<15$ years $(\%)$ & Total $(\%)$ & P-Value & Chi square \\
\hline 2007 & $22(2.49)$ & $15(1.70)$ & $37(4.19)$ & 0.07 & 38.88 \\
2008 & $48(5.43)$ & $20(2.26)$ & $68(7.69)$ & & \\
2009 & $77(8.71)$ & $69(7.81)$ & $146(16.52)$ & & \\
2010 & $82(9.28)$ & $60(6.79)$ & $142(16.06)$ & & \\
2011 & $29(3.28)$ & $30(3.93)$ & $59(6.67)$ & & \\
2012 & $52(5.88)$ & 51() 5.77 & $103(11.65)$ & \\
2013 & $46(5.20)$ & $36(4.07)$ & $82(9.28)$ & & \\
2014 & $50(5.66)$ & $49(5.54)$ & $99(11.20)$ & & \\
2015 & $35(3.96)$ & $36(4.07)$ & $71(8.03)$ & & \\
2016 & $32(3.62)$ & $5(0.57)$ & $77(8.71)$ & & \\
Total & $473(53.51)$ & $411(46.49)$ & $884(100)$ & & \\
\hline
\end{tabular}

Table 5: Site of bite of dog bites on victims in Plateau State, Nigeria Jan. 2007- Dec. 2016

\begin{tabular}{llllllllllll}
\hline Year/Site of bite & 2007 & 2008 & 2009 & 2010 & 2011 & 2012 & 2013 & 2014 & 2015 & 2016 & Total (\%) \\
\hline Head & 0 & 0 & 2 & 1 & 2 & 1 & 0 & 2 & 1 & 0 & $9(1.02)$ \\
Hand & 4 & 7 & 12 & 7 & 2 & 11 & 12 & 9 & 11 & 2 & $77(8.71)$ \\
Abdomen & 1 & 0 & 0 & 1 & 1 & 1 & 0 & 1 & 1 & 1 & $7(0.79)$ \\
Buttocks & 0 & 3 & 2 & 4 & 1 & 5 & 3 & 1 & 0 & 3 & $22(2.49)$ \\
Leg & 23 & 16 & 33 & 30 & 13 & 21 & 24 & 27 & 23 & 27 & $237(26.81)$ \\
Multiple & 2 & 1 & 3 & 2 & 0 & 2 & 1 & 0 & 1 & 1 & $13(1.47)$ \\
Unknown & 7 & 41 & 94 & 97 & 40 & 62 & 42 & 59 & 34 & 43 & $519(58.71)$ \\
Total & 37 & 68 & 146 & 142 & 59 & 103 & 82 & 99 & 71 & 77 & $884(100)$ \\
\hline
\end{tabular}

P-Value $0.004^{*} \quad(\mathrm{P}<0.05)$

Chi square $\quad 85.36$

(Sabo et al., 2008; Konzing et al., 2015) could have played a role in the high incidence of dog bite cases reported in this study. There was no vaccination of dogs against rabies at the dog markets and no veterinary worker was present at the markets to the best of our knowledge. In the year 2007, only 37 cases were recorded, but the incidences of dog bite cases increased significantly in 2009 and 2010 to 146 cases and 142 cases, respectively.
Increase in awareness on the dangers of rabies could have prompted most of the victims to report cases of dog bites to the hospitals in order to receive human anti-rabies post exposure prophylaxis vaccine, which is in agreement with the observation of Garba et al. (2014).

Furthermore, results from this study indicated that Vom Christian Hospital (VCH) had the highest number of cases (425 cases) recorded which 
represents $48 \%$ of 884 dog bite cases reported followed by 265 dog bite cases (30\%) from Plateau State Specialist Hospital (PSH). The two hospitals are both located in Jos South Local Government Area (LGA), thereby making the findings consistent with the reports of Kujul et al. (2012) who reported that Jos south had the highest number of dog bite cases. $\mathrm{VCH}$ is located more in the rural community which is on the outskirts of Jos metropolis which further confirms the fact that $92 \%$ of dog population in Nigeria are in the rural settlements (RIM, 1992). Also, the constant availability of human anti-rabies post-exposure prophylaxis vaccine was another factor responsible for the high number of dog bite victims recorded by $\mathrm{VCH}$.

The highest number of dog bite cases (85 cases) reported to the hospitals was in April. This is in agreement with the work of Garba et al. (2014) in Niger State of Nigeria. High incidence of dog bite (81 cases) was also reported in October which is similar to the findings of Otolorin et al. (2014) in Abia State of Nigeria where there is increased frequency of dog bites between the months of October and December that coincides with festive activities. Moreover, the breeding period for dogs falls within October to December of the dry season (Garba et al., 2005). This study also revealed that there were 472 (53.39\%) male victims of dog bites, as against 412 (46.61\%) females. This is similar to the reports of Aghahowa \& Ogbeoveon (2010) and Otolorin et al. (2014). In the African tradition, men are expected to provide for the daily needs of their families; in the attempt to meet these needs they may fall victims of dog bite (Otolorin et al., 2014).

Based on the age distribution of dog bite, there were more adults above 15 years of age (53.51\%) being victims of dog bite than children below 15 years of age. This agrees with the studies of Sabo (2009); Garba et al. (2014) and Konzing et al. (2015) that more dog bite cases were reported in adults, but contrary to the study that children had more dog bite cases (Abubakar \& Bakari, 2012).

The site of dog bite not documented, was recorded as unknown in $58.71 \%$ of the cases. This may be an indication that proper records were not kept by some of the selected hospitals. If proper records were kept by all the hospitals, the result could have been in agreement with the results obtained in Niger State that $81 \%$ of the victims were bitten on the leg (Garba et al., 2014) and the findings in Abia State that the leg had the highest number of bites than other parts of the body (Otolorin et al., 2014).
It can be concluded from this study that there was a high incidence of dog bites in Plateau State for the period of the study. The presence of two popular dog markets located in Jos south and Kanke Local Government Areas of the state could possibly have played a significant role in the high incidences of dog bite cases recorded in this study. There is a tendency of some of the dogs escaping from the dog market to become a source of transmission of rabies to other dogs and the public. Available records have shown that some people get attracted to the dogs which they buy and take home as guard dogs without knowing the vaccination status of the dogs, thereby contributing to the high dog bite cases reported in Plateau State.

Hospitals in Plateau State should endeavour to improve on their record keeping on reported dog bite cases as this will help health workers in planning of rabies control programmes in the state.

\section{Aknowledgement}

The authors are grateful to the Ministry of Health Plateau State and the Plateau State Hospital Management Board for approving the application for ethical clearance. I appreciate all the hospitals and clinics that allowed access to their medical records and the management of NVRI Vom for the privilege to embark on this research.

\section{Conflicts of Interest}

The authors declare they have no conflict of interest.

\section{References}

Abubakar SA \& Bakari AG (2012). Incidence of dog bite injuries and clinical rabies in a tertiary health care institution: A 10-year retrospective study. Annal of African Medicine, 11(2): 108-111.

Aghahowa SE \& Ogbeoveon RN (2010). Incidence of dog bite and anti-rabies vaccine utilization in the University of Benin Teaching Hospital, Benin City, Nigeria: A 12-year assessment. Vaccine, 28(30): 4847-4850.

Bata SP, Dzikwi AA \& Ayika DG (2011). Retrospective study of dog bite cases reported to ECWA veterinary clinic, Bukuru, Plateau State, Nigeria. Science World Journal, 6(4): 17-19.

Blench RM, Daniel P \& Umaru H (2003). Access Rights and Conflict over Common Pool Resources on the Jos Plateau, Nigeria. Report to Conflict Resolution Unit, World Bank. 
http://homepage.ntlworld.com/roger blen ch/RBOP.htm, retrieved 12-03-2013.

Chomel BB \& Trotignon J (1992). Epidemiologic surveys of dog and cat bites in the Lyon area, France. European Journal of Epidemiology, 8(4): 619-624.

Fekadu M (1975). Asymptomatic non-fatal canine rabies. Lancet, 1: 569.

Garba A, Oyetunde IL, Kumbish PR, Clement AM, Chiko KL, Ahmed JS, Lapang H, Dashe Y, Tunde $O$ \& Banyigyi SA (2005). A retrospective study of biting dogs and rabies in Vom, Plateau State. Vom Journal of Veterinary Sciences, 1(2): 57-63.

Garba A, Umoh JU, Kazeem HM, Dzikwi AA, Yahaya MS, Zaharadeen A, Konzing L \& Odeh EL (2014). Hospital records (2006 - 2013) of dog bite cases and laboratory confirmation of dog rabies in Niger State, Nigeria. International Journal of Animal and Veterin ary Advances, 6(2): 88-92.

Goonaratna C, Dodet B \& Meslin FX (1997). Human Rabies In: Rabies Control in Asia. Elsevier, Paris. Pp 188-190.

Konzing L (2014). A Study on Dog-Human Interface Concerning Risk of Rabies in Dog Meat Processors in Plateau State, Nigeria. MSc thesis, Department of Veterinary Public Health and Preventive Medicine, Faculty of Veterinary Medivine, Ahmadu Bello University, Zaria. Pp 26-77.

Konzing L, Umoh JU \& Dzikwi AA (2015). Trade Dog Dog Meat Processors Interface in Rabies Transmission. International Journal of Applied Research, 1(11): 83-91.

Kujul NB, Karshima NS, Chukwuedu AA, Olaleye S \& Salisu AA (2012). Retrospective study on puppy bite reported to veterinary clinic Federal College of Animal Health and
Production Technology, Vom, Plateau State from 2004 to 2010. Nigerian Veterinary Journal, 33(3): 549-557.

Otolorin GR, Umoh JU \& Dzikwi AA (2014). Cases of dog bite in Aba, Abia State Nigeria and Its public health significance. International Journal of Tropical Disease and Health, 4(10): 1097-1103.

Peters V, Sottiaux M, Appelboom J \& Kahn A (2004). Posttraumatic stress disorder after dog bites in children. Journal of Pediatrics, 144(4): 121-122.

RIM (1992). Federal Department of Pest Control Services. Nigerian Livestock Resources, Vol I, National Synthesis, Resources Inventory and Management Limited, Jardine House 1 Wesley Street St. Helier, Jersey, JE4 8UD, U.K. ISB 189802801 X Pp 1-37.

Sabo G, Umoh JU, Sackey AKB, Ahmad A \& Okolocha EC (2008). The role of dog trade in the epidemiology of rabies: A review. Veterinary Clinical Practice Bulletin, 1 (1): 63-72.

Sabo GNK (2009). The Role of Dog Trade in the Epidemiology of Rabies in Plateau state, Nigeria. MSc Thesis, Department of Veterinary Public Health and Preventive Medicine, Faculty of Veterinary Medicine, Ahmadu Bello University, Zaria, Nigeria. Pp 13-50.

WHO (2005). WHO Expert Consultation on Rabies: First Report, Geneva 27, Switzerland. World Health Organisation Technical Report Series, 931: 1-121.

WHO (2013). WHO Expert Consultation on Rabies: second report. Geneva 27, Switzerland. World Health Organisation, Technical Report Series, 982: 1-30. 